\title{
Normative Misperception and the Impact of Descriptive and Injunctive Norms on College Student Gambling
}

\author{
Mary E. Larimer and Clayton Neighbors \\ University of Washington
}

\begin{abstract}
Two studies examined college student gambling as a function of descriptive and injunctive social norms. It was expected that individuals would overestimate the descriptive norm and that both descriptive and injunctive norms would uniquely predict gambling behavior and problem gambling. In Study 1, self-reported gambling frequency among 317 college students was found to be lower than perceived typical college student gambling behavior. Study 2, which included 560 college students, replicated the results of Study 1 and revealed similar findings with respect to perceived and actual descriptive norms for gambling expenditure. Perceived descriptive and injunctive norms uniquely predicted self-reported gambling frequency, expenditure, and negative consequences related to gambling. The utilization of social norms-based interventions to reduce problem gambling among college students is discussed.
\end{abstract}

With annual revenue of more than $\$ 47$ billion in 1996 and growing, gambling has surpassed spectator sports, box office sales, live entertainment, theme parks, and cruises in competition for U.S. leisure dollars (Christiansen, 1998). A portion of the revenue from legal gambling enterprises goes to support local and state governments, making gambling an important source of revenue for these entities. It is unfortunate that, with the expansion of legalized gambling in the United States, problems related to gambling have also risen, and disordered gambling now represents an important U.S. public health problem (Cunningham-Williams, Cottler, Compton, \& Spitznagel, 1998; Korn \& Shaffer, 1999; Shaffer, Hall, \& Vander Bilt, 1999). An estimated $1.6 \%$ of the general adult population of the United States meet diagnostic criteria for pathological gambling (American Psychiatric Association, 1994), and an additional 3.85\% report subclinical (Level 2) gambling problems (Shaffer et al., 1999). College students appear to be at particular risk for experiencing problem or pathological gambling disorders, with rates nearly double that of general population adults (Lesieur et al., 1991; Neighbors, Lostutter, Larimer \& Takushi, 2001; Shaffer et al., 1999; Winters, Bengston, Dorr, \& Stinchfield, 1998). Winters et al. (1998) found that approximately $87 \%$ of Minnesota college students reported gambling in the previous year, and although the prevalence of disordered gambling was relatively low, it was still more than twice the state estimate for older adults.

The disproportionate impact of disordered gambling on adolescents and young adults in the college setting is of significant concern because of the health and social consequences of problem gambling behavior. These include high rates of stress-related phys-

Mary E. Larimer and Clayton Neighbors, Department of Psychiatry and Behavioral Sciences, University of Washington.

Clayton Neighbors is now at the Department of Psychology, North Dakota State University.

Correspondence concerning this article should be addressed to Mary E. Larimer, Department of Psychiatry and Behavioral Sciences, University of Washington, Box 356560, Seattle, Washington 98195. E-mail: larimer@u.washington.edu ical symptoms (Lesieur, 1998; Lorenz \& Yaffee, 1986); attempted and completed suicides (Cunningham-Williams et al., 1998; Phillips, Welty, \& Smith, 1997); significant work, educational, financial, and familial disruption; high rates of comorbidity with other addictive and psychiatric disorders (Gupta \& Derevensky, 2000); and criminal arrest and convictions (Bland, Newman, Orn, \& Stebelsky, 1993; Blaszczynski \& McConaghy, 1994; Ladouceur, Dube, \& Bujold, 1994).

Social psychological explorations of gambling behavior have typically focused on cognitive biases (Carroll \& Huxley, 1994; Gilovich, 1983), heuristic processing (Denes-Raj \& Epstein, 1994), and control constructs (e.g., illusions of control: Bouts \& Van-Avermaet, 1992; Friedland, Keinan, \& Regev, 1992; Hong \& Chiu, 1988; desire for control: Burger \& Smith, 1985). It is surprising that almost no research has examined social influences on gambling behavior, despite the fact that social reasons are among the most frequently reported reasons for gambling among college students (Neighbors, Larimer, Lostutter, \& Cronce, 2001).

Social norms represent a core construct in the field of social psychology and are presumed by many individuals in the field to represent a powerful source of influence on the behavior of human beings (Berkowitz, 1997; Cialdini, Reno, \& Kallgren, 1990; Fishbein \& Ajzen, 1975). The term social norm has often been used interchangeably to refer to two distinct types of social influence: the perception of what is (often referred to as a descriptive norm; Reno, Cialdini, \& Kallgren, 1993; Deutsch \& Gerard, 1955) and the perception of what should be (variously referred to as a subjective or injunctive norm; Ajzen, 1991; Cialdini et al., 1990; Sheeran \& Orbell, 1999). ${ }^{1}$ The lack of distinction in the literature between descriptive and injunctive norms has led to both theoretical and pragmatic difficulties in evaluating normative influences on behavior (Berkowitz, 1997; Reno et al., 1993).

\footnotetext{
${ }^{1}$ The terms subjective norms and injunctive norms have both been used in the literature to describe the perceived approval or disapproval of important others regarding a particular behavior. We use the term injunctive norms consistently to avoid confusion.
} 
Nonetheless, both descriptive and injunctive norms figure prominently in several influential theories of behavior and behavior change. For example, social learning theory (Bandura, 1986) and problem behavior theory (Donovan, Jessor, \& Jessor, 1983) emphasize modeling of behavior and perceived descriptive norms as important determinants of individual health behavior. Similarly, Festinger's (1954) social comparison theory emphasizes descriptive norms as an important referent for evaluating one's own behavior and skills against others' accomplishments. Ajzen (1991), in contrast, emphasized injunctive norms in the theory of reasoned action (Ajzen \& Fishbein, 1980; Fishbein \& Ajzen, 1975) and his reformulated theory of planned behavior (Ajzen, 1991).

Research indicates that perceptions of both descriptive and injunctive norms can be inaccurate, in one of several ways. For example, false consensus effects, whereby individuals inaccurately conclude that other people's attitudes or behaviors are similar to their own, can occur (Marks \& Miller, 1987). Alternatively, false uniqueness effects, whereby individuals inaccurately conclude that their behavior or attitudes are dissimilar from others, can occur (Marks, 1984; see Miller \& McFarland, 1991, for a review). Pluralistic ignorance (Prentice \& Miller, 1993) is a similar construct used to describe circumstances in which there is a shared misperception that others' behaviors or attitudes are different from one's own private behavior and attitudes, despite few differences in public behavior. Combined with pressures toward conformity, as described by Asch (1952), these types of misperceptions of descriptive and injunctive norms are hypothesized to be as important as accurate norms in influencing behavior of individuals in social groups. Indeed, research across a variety of health and social behaviors has demonstrated a connection between perceived norms and individual behavior. For example, perceived descriptive norms have been shown to be related to alcohol use and abuse (Baer, Stacy, \& Larimer, 1991; Perkins, Meilman, Leichliter, Cashin, \& Presley, 1999; Reis \& Riley, 2000), condom use (Buunk, Bakker, Siero, van den Eijinden, \& Yzer, 1998), and littering (Cialdini et al., 1990). Similarly, perceived injunctive norms have been shown to be related to social behaviors such as littering and aggression (Berkowitz, 1994; Cialdini et al., 1990; Reno et al., 1993), as well as alcohol consumption and other health behaviors (Berkowitz \& Perkins, 1986; Van Empelen, Schaalma, Kok, \& Jansen, 2001). For example, perceiving that important others disapprove of alcohol consumption is associated with less consumption. There remain, however, continuing questions about the range of behaviors that are influenced by perceived descriptive and injunctive norms; the degree to which descriptive and injunctive norms represent distinct sources of influence on behavior; and the extent to which gender, ethnicity, and other demographic variables interact with normative perceptions to influence behavior.

Given the central explanatory role of perceived descriptive and injunctive norms in several influential theories of human behavior, the relative dearth of literature applying this theoretical framework to gambling is especially puzzling. Only two empirical studies identified in the published literature have evaluated social norms with respect to gambling behavior. In the first study, Moore and Ohtsuka (1999) evaluated the role of injunctive norms and attitudes (based on the theory of reasoned action; Fishbein \& Ajzen, 1975) in predicting gambling intentions, behavior, and problems in a college student sample of convenience. The results indicated that injunctive norms were related to gambling frequency in this sample, but they were not significantly related to intentions to gamble, or to gambling problems as measured by the South Oaks Gambling Screen (SOGS; Lesieur \& Blume, 1987). Descriptive norms were not included in Moore and Ohtsuka's study. The second article identified in the literature on gambling norms is that of Sheeran and Orbell (1999), who reported four studies evaluating the contribution of both descriptive and injunctive norms to prediction of lottery-playing behavior among college students, within the context of the theory of planned behavior (Ajzen, 1991). Specifically, Sheeran and Orbell tested whether the addition of descriptive norms and anticipated regret would add to the prediction of intentions to play the lottery and actual frequency of lottery playing after accounting for attitudes, perceived behavioral control, and injunctive norms as suggested by the theory of planned behavior. Their results indicated that perceived descriptive norms consistently predicted intentions to play the lottery across all the studies and, in a 2-week prospective study, intentions were related to actually playing the lottery. Perceived injunctive norms were related to intentions to play the lottery among a general population, but not among their college student samples. Although Sheeran and Orbell's work is theoretically strong and represents an advance in the field of gambling research, several issues have not yet been addressed, including the accuracy of perceived descriptive norms. In addition, previous work has not incorporated standardized measures of gambling behavior or negative consequences and included only lottery playing as a gambling outcome. Previous work has not examined the extent to which pluralistic ignorance is represented in perceived descriptive norms of gambling. Although Sheeran and Orbell posited that education regarding accurate descriptive norms may be an effective intervention for gambling problems, on the basis of the observed relationship between descriptive norms and gambling in their studies, there is no information in the literature to evaluate whether the normative misperceptions found with respect to other health risk behaviors are also present with respect to gambling.

The present research was designed to replicate and extend prior research on social norms (both descriptive and injunctive) with respect to gambling behavior in college populations. Study 1 was designed to evaluate misperceptions of descriptive norms for gambling frequency and the degree to which these perceptions are related to gambling behavior. In Study 2 we replicated and extended this line of research by evaluating perceptions of both injunctive norms and descriptive norms and evaluating the relative utility of both types of norms in predicting concurrent gambling behavior and gambling-related negative consequences. We hypothesized that students would report higher descriptive norms for gambling frequency and quantity (expenditure) than the actual mean of their own self-reported behavior and that both perceived descriptive and injunctive norms would uniquely predict gambling behavior and negative consequences in this population. We further hypothesized that descriptive and injunctive norms would represent unique sources of potential influence on gambling behavior.

\section{Study 1}

The purpose of Study 1 was to provide a preliminary investigation of the accuracy or misperception of perceived descriptive norms of gambling among college students and the extent to which 
this perception of the descriptive norm is related to self-reported gambling behavior. We expected that the perceived norm of gambling frequency would be higher than the actual norm and that individuals who gambled more frequently would be most likely to overestimate the norm. We were interested in, but had no specific expectations regarding how, this might differ across demographic characteristics.

\section{Method}

\section{Participants}

Participants included 317 undergraduate psychology students (168 men and 146 women; 3 students did not indicate their sex) at a large west coast university. The average age of participants was 19.15 years $(S D=1.84)$. Ethnicity was $65.3 \%$ Caucasian, 24.3\% Asian/Pacific Islander, and 10.4\% other. Participants were freshmen $(62.7 \%)$, sophomores (21.4\%), juniors $(11.5 \%)$, and seniors $(4.4 \%)$. This sample was demographically similar to the university's undergraduate population, which in the year 2000 was approximately $52 \%$ female and $22 \%$ Asian/Pacific Islander.

\section{Procedure}

At the beginning of each academic quarter, interested psychology students are invited to participate in a mass testing session during which a variety of survey and screening instruments are distributed. The survey used in this study was among these questionnaires. Participants were urged to answer items honestly and were reminded that all answers would remain anonymous. The questionnaire included demographic items and two items taken from the Gambling Quantity and Perceived Norms scale (GQPN; Neighbors, Lostutter, et al., 2001). One of these items assessed gambling frequency by asking participants how often they gamble, on a scale that ranged from 1 to 10 (never, once a year, 2-3 times per year, every other month, once a month, 2-3 times per month, weekly, more than once per week, every other day, and every day). Another item assessed the perceived descriptive norm for gambling frequency by asking participants how often they thought the average college student gambles, on a scale that ranged from 1 to 10 , with the same anchors. The questionnaire also included additional items not relevant to the present research.

\section{Results}

Distribution analyses reveled extreme departures from normality for reported gambling frequency (Shapiro-Wilk's W $=.79$, $p<.0001$ ) and perceived gambling frequency (Shapiro-Wilk's $\mathrm{W}=.90, p<.0001)$. We consequently conducted nonparametric tests for all analyses. All significance levels are two-tailed.

A few students did not respond to one or more of the survey items. We used pairwise deletion in the analyses; thus, discrepancies in degrees of freedom are due to missing data. Students' reported gambling was relatively infrequent $(M d n=$ once per year or less). Men reported gambling more frequently than women (Wilcoxon Rank-Sum for independent samples, $z=-6.23, p<$ .0001). In Table 1, frequencies of reported gambling frequency by gender are reported. Older students reported gambling somewhat more frequently, Spearman's $\rho(315)=.14, p<.05$. Reported frequency did not differ as a function of ethnicity.

When students were asked how often they thought "the average college student gambles," perceptions were somewhat higher $(M d n=$ every other month). Frequency distributions of responses for actual and perceived gambling frequency are presented in Figure 1. As expected, the perceived gambling frequency norm
Table 1

Study 1 Frequencies of Reported Gambling Frequency by Gender

\begin{tabular}{lrrrrr}
\hline & \multicolumn{2}{c}{ Women } & & \multicolumn{2}{c}{ Men } \\
\cline { 2 - 3 } \cline { 5 - 6 } \multicolumn{1}{c}{ Frequency } & $n$ & $\%$ & & $n$ & $\%$ \\
\hline Never & 84 & 58 & & 43 & 26 \\
Once a year or less & 29 & 20 & & 45 & 27 \\
2-3 times per year & 26 & 18 & & 36 & 21 \\
Every other month & 3 & 2 & & 13 & 8 \\
Once a month & 1 & 1 & 14 & 8 \\
2-3 times per month & 1 & 1 & & 12 & 7 \\
Weekly & 0 & 0 & & 2 & 1 \\
More than once per week & 2 & 1 & 3 & 2 \\
\hline
\end{tabular}

was higher than the actual frequency norm (Wilcoxon Rank-Sum for related samples, $z=-12.12, p<.0001$ ). In addition, students who perceived the gambling norm as being higher reported gambling more frequently, Spearman's $\rho(315)=.21, p<.001$.

In examining perception of the gambling frequency norm as a function of demographic characteristics, we found no differences with regard to sex or age. Perceived norms did, however, differ as a function of ethnicity, Kruskal-Wallis $\chi^{2}(2, N=315)=6.37$, $p<.05$. Specifically, Asians/Pacific Islanders perceived a higher frequency norm than did Caucasians (Wilcoxon $z=2.29, p<$ $.05)$.

\section{Study 2}

The purpose of Study 2 was to replicate Study 1 with respect to the misperception of descriptive norms and to further explore the relation between perceived norms (descriptive and injunctive) and gambling behavior and problems. For this study, only students who had ever gambled at least once in their lives were recruited. Whereas in Study 1 we examined only descriptive norms associated with gambling frequency, in Study 2 we added perceptions of expenditure norms. In addition, Study 2 included multiple gambling indices. We expected that perceived descriptive norms of gambling frequency and expenditure would be greater than actual descriptive norms. We also expected that both perceived descriptive and injunctive norms would be uniquely associated with problem gambling. We were further interested in examining demographic differences in perceived descriptive and injunctive norms.

\section{Method}

\section{Participants}

Participants included 560 college students (204 men and 347 women; 9 respondents did not indicate their sex) enrolled in undergraduate psychology courses at a large west coast university. Participants were recruited via sign-up sheets and received extra credit for participation. The average age of participants was 19.23 years $(S D=1.78)$. Ethnicity was $59.4 \%$ Caucasian, 33.8\% Asian/Pacific Islander, and 6.8\% other. Participants were freshmen $(55.5 \%)$, sophomores $(28.2 \%)$, juniors $(11.4 \%)$, and seniors (4.9\%). Compared with the university's undergraduate population, women and Asian/Pacific Islander participants were somewhat overrepresented in this sample. 


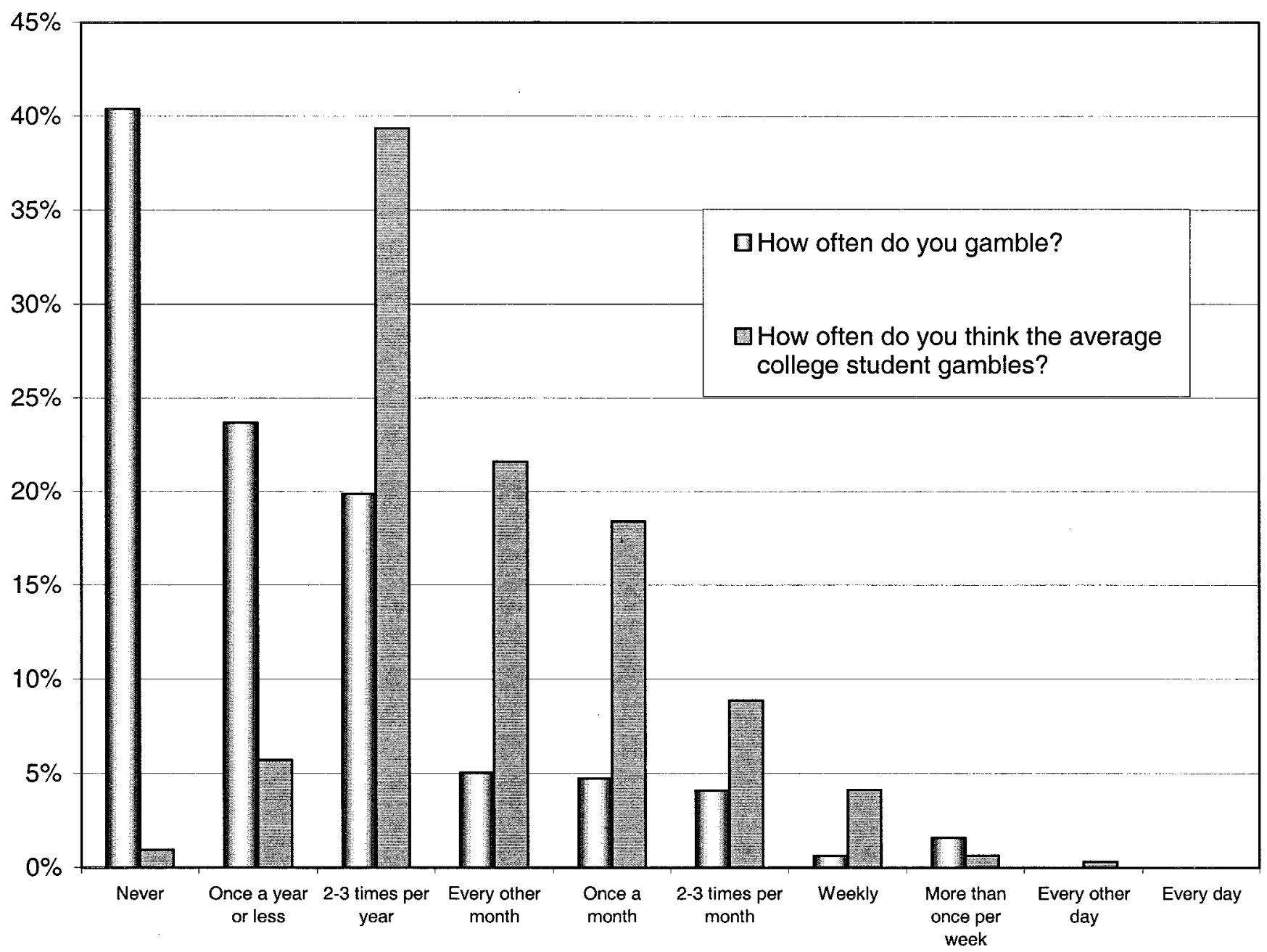

Figure 1. Study 1 frequency distributions for reported gambling frequency and perceived frequency norm.

\section{Procedure}

Participants completed measures in small groups with no communication between participants. They were urged to answer all items honestly and were reminded that all answers would remain anonymous. After the assessment, participants were debriefed and thanked. All procedures were reviewed and approved by the departmental human subjects review committee.

\section{Measures}

The Gambling Quantity and Perceived Norms Scale (Neighbors, Lostutter, et al., 2001) includes subscales designed to measure gambling expenditure and perceived descriptive gambling norms.

Gambling expenditure. The Expenditure subscale includes six items assessing gambling wins and losses. Example items include "Approximately how much money have you spent (lost) gambling in the past year?", with 10 response options ranging from less than $\$ 25$ to more than $\$ 2,000$. Coefficient alpha was .89. An additional item assesses disposable income: "Approximately how much spending money (not devoted to bills) do you have each month?" and includes 11 response options, ranging from less then $\$ 50$ to more than $\$ 500$. Gambling expenditure was calculated as the mean of the six expenditure items residualized on disposable income; thus, scores reflect gambling expenditure controlling for relevant income differences.

Perceived descriptive norms. The Perceived Norms subscale includes five items assessing perceptions of typical college student gambling behavior. One item (the same as used in Study 1) addresses perceived frequency norms. Four items assess perceived norms for monthly and yearly wins and losses. Two items ask about perceived typical yearly gambling expenditure ("How much money do you think the average college student wins gambling per year?" and "How much money do you think the average college student loses gambling per year?"). These items include 10 response options, ranging from less than $\$ 25$ to more than $\$ 2000$. Two items ask about perceived typical monthly gambling expenditure: "How much money do you think the average college student wins gambling per month?" and "How much money do you think the average college student spends (loses) gambling per month?" These items include 10 response options ranging from less than $\$ 5$ to more than $\$ 500-$ $\$ 1000$. Coefficient alpha was .84.

Injunctive norms. Injunctive norms were assessed with a 12-item scale taken from Moore and Ohtsuka (1999) with language modified for a U.S. sample (i.e., "pokies" was rephrased as poker machines). Items assess the extent to which close others (family and friends) approve of gambling. Items include "Most of my friends approve of gambling," "My family 
approves of gambling," "People in my family gamble sometimes," "People in my family often go to places where gambling occurs," "My family members spend $\$ 20$ or more/week on gambling," "My family members spend $\$ 100$ or more/week on gambling," "Most of my friends gamble sometimes," "My friends often go out to places where gambling occurs," "My friends would disapprove of me playing poker machines," "My family would disapprove of me playing poker machines," "My friends would disapprove of me buying a lottery ticket," and "My family would disapprove of me buying a lottery ticket." Participants responded using 5-point (disagree-agree) Likert-type scales. Scores were calculated as the mean of the 12 items. Higher scores indicate injunctive norms favoring gambling. Coefficient alpha in this study was .78 .

The SOGS (Lesieur \& Blume, 1987) is a widely used self-administered screening instrument for pathological gambling. It contains 20 scored items that correlate highly with Diagnostic and Statistical Manual of Mental Disorders (3rd ed., rev.; American Psychiatric Association, 1987, 4th ed.; American Psychiatric Association, 1994) diagnoses of pathological gambling and has demonstrated validity and reliability among university students (Beaudoin \& Cox, 1999; Ladouceur et al., 1994; Lesieur et al., 1991; Neighbors, Lostutter, et al., 2001). Sample scored items include "Have you ever felt like you would like to stop gambling but didn't think you could?" and "Have you ever lost time from work (or school) due to gambling?" The SOGS is typically used to screen probable pathological gamblers with a cutoff score of 5, or subclinical "problem," or Level 2 gamblers with a cutoff score of 3 (Shaffer et al., 1999). Continuous raw scores (possible range: 0-20) were used in the present study.

Gambling frequency. The SOGS also includes nonscored items assessing frequency of gambling, for which respondents indicate how frequently they have engaged in various gambling activities (e.g., bet on horses, went to a casino, played cards for money) from 0 (never) to 2 (once a week or more). Consistent with previous research (e.g., Moore \& Ohtsuka, 1999), we created a gambling frequency index based on this item by taking the mean of reported frequency for each type of gambling activity.

The Gambling Problem Index (GPI; Neighbors, Lostutter, et al., 2001) consists of 20 items designed to assess negative gambling consequences. For each item, respondents are asked to indicate how many times, on a scale that ranges from 1 (never) to 5 (more than 10 times), during the previous 6 months they experienced a negative consequence while gambling or as a result of gambling. Sample items include "Kept gambling when you promised yourself not to," "Neglected your responsibilities," "Missed out on other things because you spent too much money on gambling." The GPI score was calculated as the sum of items in which participants reported experiencing the gambling related consequence at least once during the previous 6 months. Coefficient alpha was .84 .

\section{Results}

Distribution analyses reveled departures from normality for reported gambling frequency (Shapiro-Wilk's W $=.95, p<$ .0001 ), reported expenditure (Shapiro-Wilk's W $=.71, p<$ .0001 ), perceived descriptive gambling norms (Shapiro-Wilk's $\mathrm{W}=.96, p<.0001$ ), and injunctive gambling norms (ShapiroWilk's $\mathrm{W}=.99, p<.01)$. We consequently conducted nonparametric tests for all analyses. All significance levels are two-tailed.

\section{Accuracy of Perceived Descriptive Gambling Norms}

We analyzed the accuracy of perceived descriptive gambling norms with a series of Wilcoxon tests examining differences between perceived frequency and expenditure norms and actual norms based on reported behavior. As expected, perceived frequency and expenditure norms were consistently higher than actual norms based on sample means. Medians and summary results for perceived versus actual norms for gambling frequency and expenditure are presented in Table 2. Frequency distributions of responses for actual and perceived gambling expenditure norms are depicted in Figure 2.

\section{Perceived Descriptive Versus Injunctive Norms}

Perceived descriptive and injunctive norms were unrelated to each other in this sample, Spearman's $\rho(560)=.02, p=.63$. We conducted a series of ordinal regressions to examine relations of social norms with problem gambling. Gambling frequency, expenditure, negative consequences, and SOGS scores were regressed onto perceived descriptive and injunctive norms. The results are presented in Table 3 and reveal that perceiving gambling as more prevalent was uniquely associated with greater gambling frequency and expenditure, more negative gambling-related consequences, and higher SOGS scores. Similarly, perceiving important others as approving of gambling was associated with greater gambling frequency and expenditure and more negative consequences, although injunctive norms were not related to SOGS scores.

We examined demographic differences in injunctive norms separately for perceived descriptive and injunctive norms. Examination of perceived descriptive norms as a function of age, sex, and ethnicity revealed that women perceived gambling as more prevalent than did men (Wilcoxon $z=-4.25, p<.0001$ ), although both overestimated actual gambling prevalence. In addition, perceived descriptive norms differed by ethnicity, Kruskal-Wallis $\chi^{2}(2, N=560)=57.34, p<.0001$. Specifically, Caucasians perceived gambling as less prevalent than did Asian/Pacific Islander participants or participants of other ethnicities (Wilcoxon $z=-7.49, p<.0001)$.

The analysis of injunctive norms as a function of demographic characteristics also revealed effects of sex (Wilcoxon $z=2.43$, $p<.05)$, and of ethnicity, Kruskal-Wallis $\chi^{2}(2, N=$ $560)=19.65, p<.0001$, but in opposite directions. Compared with women, men perceived important others as more approving of gambling. Specific contrast revealed that Caucasians, versus Asians/Pacific Islanders, perceived important others as more approving of gambling (Wilcoxon $z=4.41, p<.0001$ ).

\section{Discussion}

The results of Study 2 replicate and extend those of Study 1 with regard to descriptive norms; specifically, perceived descriptive

Table 2

Study 2 Median Perceived Descriptive Norms Versus Actually Reported Gambling Frequency and Expenditure

\begin{tabular}{|c|c|c|c|}
\hline $\begin{array}{l}\text { Gambling } \\
\text { outcome }\end{array}$ & $\begin{array}{l}\text { Median } \\
\text { perceived } \\
\text { norm }\end{array}$ & $\begin{array}{l}\text { Median } \\
\text { reported } \\
\text { behavior }\end{array}$ & Wilcoxon $z$ \\
\hline Frequency & Once a month & $2-3$ times per year & -20.34 \\
\hline Yearly losses & $\$ 50$ to $\$ 100$ & less than $\$ 25$ & -15.37 \\
\hline Monthly losses & $\$ 10$ to $\$ 20$ & less than $\$ 5$ & -17.19 \\
\hline Yearly wins & $\$ 50$ to $\$ 100$ & less than $\$ 25$ & -11.64 \\
\hline Monthly wins & $\$ 5$ to $\$ 10$ & less than $\$ 5$ & -14.70 \\
\hline
\end{tabular}

Note. All differences are significant at $p<.0001$. 


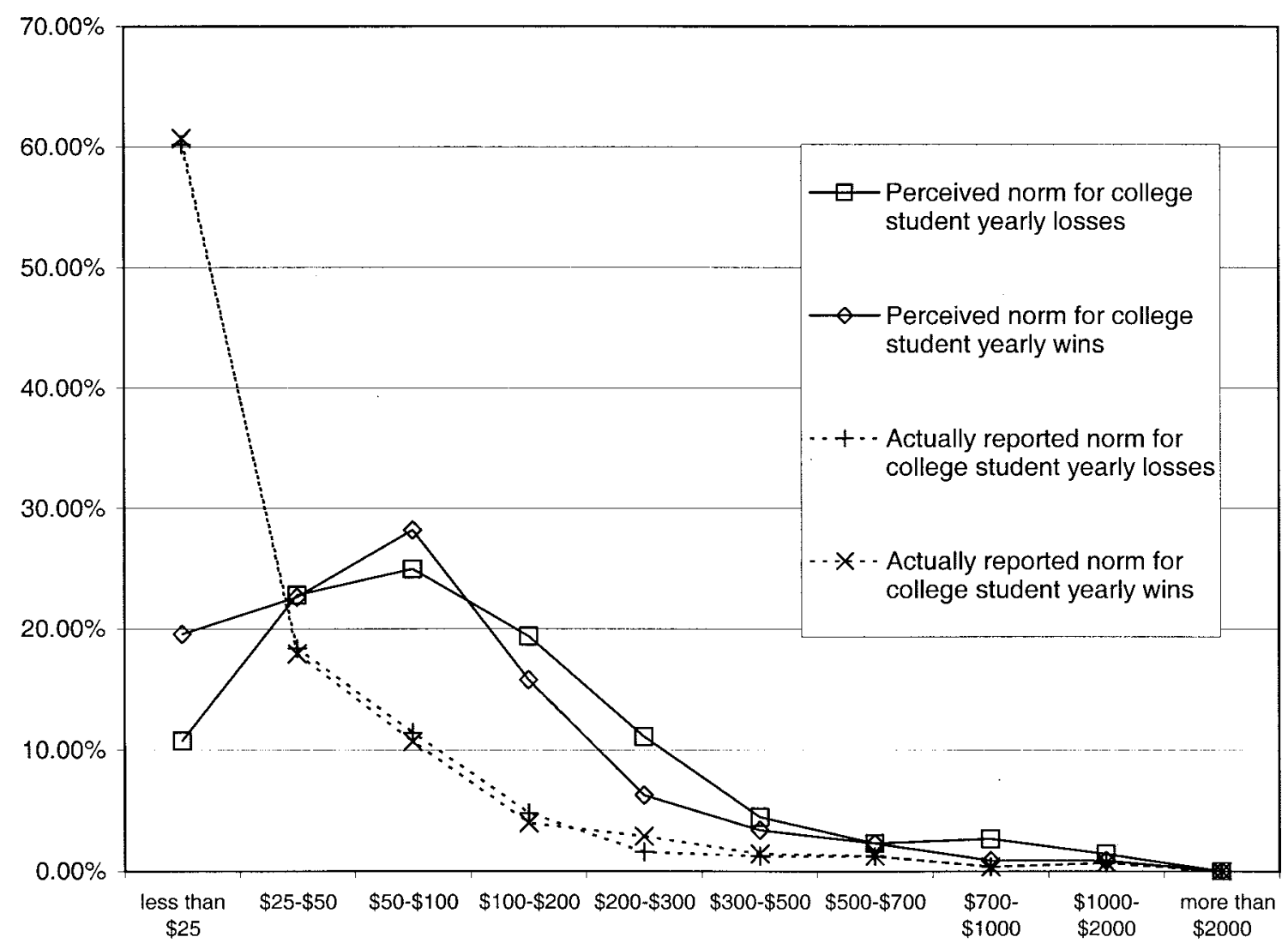

Figure 2. Study 2 frequency distributions for reported gambling expenditure and perceived expenditure norms.

norms for both frequency and expenditure exceed the actual selfreported normative behavior of the students. In addition, Study 2's results are consistent with the theory of planned behavior, and the extension of it suggested by Sheeran and Orbell (1999), in that injunctive norms and descriptive norms were independently related to self-reported gambling behavior. Both perceived descriptive norms and perceived injunctive norms were related to the experience of negative consequences of gambling. Participants who perceived their fellow students as gambling more frequently and spending more money on gambling, and perceived that important others in their life were more approving of gambling, were most likely to gamble frequently, and with greater amounts of money, and to experience more gambling-related negative consequences. Consistent with Moore and Ohtsuka's (1999) study, injunctive norms were not related to higher scores on the SOGS, but descriptive norms were related to higher SOGS scores in this study.

Some of the demographic differences in normative perceptions of both descriptive and injunctive norms were intriguing. Specifically, women perceived gambling as occurring more frequently than did men (even though men gamble more frequently than women), and Caucasian students believed significant others in their life were more approving of gambling than did Asian/Pacific Islander students, despite the fact that Asian/Pacific Islander stu-

Table 3

Study 2 Gambling Indices as a Function of Perceived Injunctive and Descriptive Norms

\begin{tabular}{lllccc}
\hline \multicolumn{1}{c}{ Outcome } & Predictor & $B$ & $S E$ & Wald $\chi^{2}$ & $p$ \\
\hline Gambling frequency & Descriptive & 0.12 & .06 & 4.65 & $<.05$ \\
& Injunctive & 1.20 & .14 & 71.02 & $<.0001$ \\
Gambling expenditure & Descriptive & 0.23 & .06 & 15.75 & $<.0001$ \\
& Injunctive & 0.70 & .14 & 26.22 & $<.0001$ \\
Gambling consequences & Descriptive & 0.21 & .06 & 11.91 & $<.001$ \\
& Injunctive & 0.41 & .15 & 7.59 & $<.01$ \\
SOGS score & Descriptive & 0.11 & .06 & 3.68 & .05 \\
& Injunctive & 0.23 & .14 & 2.52 & .11 \\
\hline
\end{tabular}

Note. $\quad$ SOGS $=$ South Oaks Gambling Screen. 
dents tend to report higher rates of gambling than do Caucasian students.

\section{General Discussion}

The current research was designed to replicate and extend prior work on social norms for gambling behavior, to contribute to the literature on perceived norms as a source of social influence, and to contribute to research on models of gambling behavior. Specifically, we sought to evaluate whether students misperceive the descriptive norms for gambling and to assess the relative contribution of perceived descriptive norms and perceived injunctive norms in predicting concurrent gambling behavior and related negative consequences for college students, a group at particularly high risk for development of problem gambling. We hypothesized that, consistent with social comparison theory (Festinger, 1954), false uniqueness (Miller \& McFarland, 1991), and pluralistic ignorance (Prentice \& Miller, 1983), students' perceptions of the descriptive norms for gambling would represent an overestimate compared with their self-reported behavior. We further predicted that both injunctive norms (Ajzen, 1991; Moore \& Ohtsuka, 1999) and descriptive norms (Sheeran \& Orbell, 1999) would be related to frequency, quantity, and negative consequences of gambling and that descriptive and injunctive norms would represent independent influences on gambling behavior.

The results of this research, both within and across the two studies, support our hypotheses. Consistent with past research on addictive behaviors (Baer et al., 1991), both studies suggested that participants overperceive descriptive norms for gambling behavior. Although perceived descriptive norms in both studies were related to self-reported gambling behavior, the misperception of the norm occurred at all levels of self-reported gambling behavior. Haines (1996) referred to this type of misperception in the alcohol field as a reign of error, suggesting that the misperception of the norm contributes to the maintenance of high-risk behaviors on college campuses.

As hypothesized, both injunctive norms and descriptive norms were related to self-reported gambling frequency, gambling expenditure, and negative consequences as measured by the GPI, although the magnitude of the relationships was consistently larger for injunctive then for descriptive norms. In contrast, and consistent with Moore and Ohtsuka's (1999) findings, injunctive norms were not related to SOGS scores in this population. Descriptive norms were related to SOGS scores, however, suggesting that experiencing problem or pathological gambling is related to perceiving that others gamble more, and more frequently, regardless of whether one perceives that one's own family and friends approve of this behavior.

Although we had no specific hypotheses regarding demographic differences, two somewhat unexpected findings emerged. First, women perceived the descriptive norms for gambling to be higher than did men, in contrast to the actual gender differences in quantity and frequency of gambling. Similarly, Asian/Pacific Islander students perceived the injunctive norms to be less positive than did Caucasian students, despite data indicating Asian/Pacific Islander students gamble more than Caucasian students do. Although these results are unexpected, it is possible that they represent measurement artifacts, such as the lack of gender- or ethnicspecific reference groups in the descriptive norm measures. It is also possible that Asian/Pacific Islander students' perception of less social approval of gambling reflects their greater level of involvement in problem gambling, likely resulting in expressed concern or disapproval by their friends and family members. Future longitudinal research is needed to evaluated perceived injunctive norms before significant gambling problems develop and to evaluate changes in this over time. Research also is needed to explore the ways in which perceived descriptive and injunctive norms may differentially influence gambling behaviors of men, women, and ethnic minority students.

Although the results of this research are consistent with our hypotheses and provide strong support for a model of gambling that incorporates the role of social influence embodied by both descriptive and injunctive norms, it is important to note the limitations of this research. First, the samples used in these studies were voluntarily recruited from psychology classes rather than through a random selection process and thus may not be representative of the larger campus population. Of note, volunteers were largely representative of the demographic makeup of the campus, with the exception of a slight overrepresentation of Asian/Pacific Islander women, consistent with the demographic composition of undergraduate psychology enrollment on the test campus. In addition, rates of problem and pathological gambling in both samples were comparable to those found in other national and international studies that used alternative sampling strategies (Lesieur et al., 1991; Shaffer et al., 1999; Volberg, 1996); thus, there does not appear to have been any systematic bias in volunteering for the studies based on students' gambling behavior. Nonetheless, replication of this research in a larger, random sample would add confidence to the findings. A second limitation of this research is that data were collected using a cross-sectional design, and thus the relationships herein cannot be assumed to be causal, although there is evidence from research on other health risk behaviors suggesting that such normative perceptions do influence future risk behavior. Longitudinal research to address causal and potentially reciprocal relations between perceived norms and gambling behavior is an important next step in this program of research. The present study also did not address the potential for misperception of the injunctive norm, which would add to the implications for prevention programming. Future research incorporating both individual attitudes regarding gambling (the mean of which would represent the true injunctive norm in a random sample of the population) and the perceived injunctive norm is needed to address this issue. Finally, all data are based on self-reports, which can be subject to problems of reliability and external validity. Steps to improve the reliability of self-reports include the use of multiple items to assess each construct and the use of standardized outcome measures with known validity and reliability in student populations. Additional steps to improve the validity of self-reports included the assurance of anonymity. Research on a variety of addictive behaviors has suggested that under these conditions self-report is generally both reliable and valid (Babor, Stephens, \& Marlatt, 1987).

Despite these limitations, the present research establishes areas for future research and has several implications for intervening with college student gamblers. Specifically, these findings suggest that incorporating feedback regarding accurate descriptive norms for gambling behavior, and potentially accurate injunctive norms, may be an important component of prevention and treatment. Recent interventions for college alcohol problems have used social 
norms-based social marketing campaigns (emphasizing accurate descriptive norms for alcohol) to successfully reduce alcohol use on campus (Haines, 1996; Johannesen, Collins, Mils-Novoa, \& Glider, 1999), and the current research suggests that adaptation of this strategy for gambling may be warranted. For example, personalized feedback could be provided to problem gambling students highlighting (a) their expenditure and frequency of gambling, (b) their perceptions of typical college student gambling frequency and expenditure, and (c) actual typical college student gambling frequency and expenditure. Several interventions for other health risk behaviors incorporate similar graphic normative feedback into individual and small-group prevention programs (Agostinelli, Brown, \& Miller, 1995; Dimeff, Baer, Kivlahan, \& Marlatt, 1999; Larimer et al., 2001), and a recent modification of this approach to gambling shows promise (Takushi et al., in press).

\section{References}

Agostinelli, G., Brown, J. M., \& Miller W. R. (1995). Effects of normative feedback on consumption among heavy drinking college students. Journal of Drug Education, 25, 31-40.

Ajzen, I. (1991). The theory of planned behavior. Organizational Behavior and Human Decision Processes, 50, 179-211.

Ajzen, I., \& Fishbein, M. (1980). Understanding attitudes and predicting social behavior. Englewood Cliffs, NJ: Prentice Hall.

American Psychiatric Association. (1987). Diagnostic and statistical manual of mental disorders (3rd ed., rev.). Washington, DC: Author.

American Psychiatric Association. (1994). Diagnostic and statistical manual of mental disorders (4th ed.). Washington, DC: Author.

Asch, S. E. (1952). Social psychology. Englewood Cliffs, NJ: Prentice Hall.

Babor, T. F., Stephens, R. S., \& Marlatt, G. A. (1987). Verbal report methods in clinical research on alcoholism: Response bias and its minimization. Journal of Studies on Alcohol, 48, 410-424.

Baer, J. S., Stacy, A., \& Larimer, M. (1991). Biases in the perception of drinking norms among college students. Journal of Studies on Alcohol, 52, 580-586.

Bandura, A. (1986). Social foundations of thought and action: A social cognitive theory. Englewood Cliffs, NJ: Prentice Hall.

Beaudoin, C. M., \& Cox, B. J. (1999). Characteristics of problem gambling in a Canadian context: A preliminary study using a $D S M-I V$-based questionnaire. Canadian Journal of Psychiatry, 44, 483-487.

Berkowitz, A. (1994). Men and rape: Theory, research, and prevention programs in higher education. San Francisco: Jossey-Bass.

Berkowitz, A. D. (1997). From reactive to proactive prevention: Promoting an ecology of health on campus. In P. C. Rivers \& E. R. Shore (Eds.), Substance abuse on campus: A handbook for college and university personnel (pp. 119-139). Westport, CT: Greenwood Press.

Berkowitz, A. D., \& Perkins, W. H. (1986). Problem drinking among college students: A review of recent research. Journal of American College Health, 35, 1-28.

Bland, R. C., Newman, S. C., Orn, H., \& Stebelsky, G. (1993). Epidemiology of pathological gambling in Edmonton. Canadian Journal of Psychiatry, 38, 108-112.

Blaszczysnki, A. P., \& McConaghy, N. (1994). Criminal offenses in Gamblers Anonymous and hospital treated pathological gamblers. Journal of Gambling Studies, 10, 99-127.

Bouts, P., \& Van-Avermaet, E. (1992). Drawing familiar or unfamiliar cards: Stimulus familiarity, chance orientation, and the illusion of control. Personality and Social Psychology Bulletin, 18, 331-335.

Burger, J. M., \& Smith, N. G. (1985). Desire for control and gambling behavior among problem gamblers. Personality and Social Psychology Bulletin, 11, 145-152.
Buunk, B. P., Bakker, A. B., Siero, F. W., van den Eijinden, R. J. J. M., \& Yzer, M. C. (1998). Predictors of AIDS-preventive behavioral intentions among adult heterosexuals at risk for HIV infection: Extending current models and measures. AIDS Education and Prevention, 10, 149-172.

Carroll, D., \& Huxley, J. A. (1994). Cognitive, dispositional, and psychophysiological correlates of dependent slot machine gambling in young people. Journal of Applied Social Psychology, 12, 1070-1083.

Christiansen, E. M. (1998). Gambling and the American economy. Annals of the American Academy of Political and Social Science, 555, 36-52.

Cialdini, R. B., Reno, R. R., \& Kallgren, C. A. (1990). A focus theory of normative conduct: Recycling the concept of norms to reduce littering in public places. Journal of Personality and Social Psychology, 58, 10151026.

Cunningham-Williams, R. M., Cottler, L. B., Compton, W. M., \& Spitznagel, E. L. (1998). Taking chances: Problem gamblers and mental health disorders: Results from the St. Louis Epidemiologic Catchment Area study. American Journal of Public Health, 88, 1093-1096.

Denes-Raj, V., \& Epstein, S. (1994). Conflict between intuitive and rational processing: When people behave against their better judgment. Journal of Personality and Social Psychology, 66, 819-829.

Deutsch, M., \& Gerard, H. B. (1955). A study of normative and informational social influence upon individual judgment. Journal of Abnormal and Social Psychology, 51, 629-636.

Dimeff, L. A., Baer, J. S., Kivlahan, D. R., \& Marlatt, G. A. (1999). Brief alcohol screening and intervention for college students. New York: Guilford Press.

Donovan, J. E., Jessor, R., \& Jessor, L. (1983). Problem drinking in adolescence and young adulthood: A follow-up study. Journal of Studies on Alcohol, 44, 109-137.

Festinger, L. (1954). A theory of social comparison processes. Human Relations, 7, 117-140.

Fishbein, M., \& Ajzen, I. (1975). Belief, attitude, intention and behavior: An introduction to theory and research. Reading, MA: Addison-Wesley.

Friedland, N., Keinan, G., \& Regev, Y. (1992). Controlling the uncontrollable: Effects of stress on illusory perceptions of controllability. Journal of Personality and Social Psychology, 63, 923-931.

Gilovich, T. (1983). Biased evaluation and persistence in gambling. Journal of Personality and Social Psychology, 44, 1110-1126.

Gupta, R., \& Derevensky, J. L. (2000). Adolescents with gambling problems: From research to treatment. Journal of Gambling Studies, 16, 315-342.

Haines, M. (1996). A social norms approach to preventing binge drinking at colleges and universities (OPE Publication No. 96-18). Washington, DC: U.S. Department of Education.

Hong, Y., \& Chiu, C. (1988). Sex, locus of control, and illusion of control in Hong Kong as correlates of gambling involvement. Journal of Social Psychology, 128, 667-673.

Johannesen, K., Collins, C., Mils-Novoa, B., \& Glider, P. (1999). A practical guide to alcohol abuse prevention: A campus case study in implementing social norms and environmental management approaches. Tucson: Campus Health Service, University of Arizona.

Korn, D. A., \& Shaffer, H. J. (1999). Gambling and the health of the public: Adopting a public health perspective. Journal of Gambling Studies, 15, 289-365.

Ladouceur, R., Dube, D., \& Bujold, A. (1994). Prevalence of pathological gambling and related problems among college students in the Quebec metropolitan area. Canadian Journal of Psychiatry, 39, 289-293.

Larimer, M. E., Turner, A. P., Anderson, B. K., Fader, J. S., Kilmer, J. R., Palmer, R. S., et al. (2001). Evaluating a brief alcohol intervention with fraternities. Journal of Studies on Alcohol, 62, 370-380.

Lesieur, H. R. (1998). Costs and treatment of pathological gambling. Annals of the American Academy of Political and Social Science, 556, 153-171.

Lesieur, H. R., \& Blume, S. B. (1987). The South Oaks Gambling Screen 
(SOGS): A new instrument for the identification of pathological gamblers. American Journal of Psychiatry, 144, 1184-1188.

Lesieur, H. R., Cross, J., Frank, M., Welch, M., White, C. M., Rubenstein, G., et al. (1991). Gambling and pathological gambling among university students. Addictive Behaviors, 16, 517-527.

Lorenz, V. C., \& Yaffee, R. A. (1986). Pathological gambling: Psychosomatic, emotional, and marital difficulties as reported by the gambler. Journal of Gambling Behavior, 2, 40-49.

Marks, G. (1984). Thinking one's abilities are unique and one's opinions are common. Personality and Social Psychology Bulletin, 10, 203-208.

Marks, G., \& Miller, N. (1987). Ten years of research on the falseconsensus effect: An empirical and theoretical review. Psychological Bulletin, 102, 72-90.

Miller, D. T., \& McFarland, C. (1991). When social comparison goes awry: The case of pluralistic ignorance. In J. Suls \& T. A. Wills (Eds.), Social comparison: Contemporary theory and research (pp. 287-313). Hillsdale, NJ: Erlbaum.

Moore, S. M., \& Ohtsuka, K. (1999). The prediction of gambling behavior and problem gambling from attitudes and perceived norms. Social Behavior and Personality, 27, 455-466.

Neighbors, C., Larimer, M. E., Lostutter, T. W., \& Cronce, J. M. (2001). Exploring college student gambling motives. Journal of Gambling Studies, 18, 361-370.

Neighbors, C., Lostutter, T. W., Larimer, M. E., \& Takushi, R. Y. (2001). Measuring gambling outcomes among college students. Journal of Gambling Studies, 18, 339-360.

Perkins, H. W., Meilman, P. W., Leichliter, J. S., Cashin, J. R., \& Presley, C. A. (1999). Misperceptions of the norms for the frequency of alcohol and other drug use on college campuses. Journal of American College Health, 47, 253-258.

Phillips, D. P., Welty, W. R., \& Smith, M. M. (1997). Elevated suicide levels associated with legalized gambling. Suicide and Life-Threatening Behavior, 27, 373-378.
Prentice, D. A., \& Miller, D. T. (1993). Pluralistic ignorance and alcohol use on campus: Some consequences of misperceiving the social norm. Journal of Personality and Social Psychology, 64, 243-256.

Reis, J., \& Riley, W. L. (2000). Predictors of college students' alcohol consumption: Implications for student education. Journal of Genetic Psychology, 161, 282-291.

Reno, R. R., Cialdini, R. B., \& Kallgren, C. A. (1993). The transsituational influence of social norms. Journal of Personality and Social Psychology, 64, 104-112.

Shaffer, H. J., Hall, M. N., \& Vander Bilt, J. (1999). Estimating the prevalence of disordered gambling behavior in the United States and Canada: A research synthesis. American Journal of Public Health, 89, $1369-1376$

Sheeran, P., \& Orbell, S. (1999). Augmenting the theory of planned behavior: Roles for anticipated regret and descriptive norms. Journal of Applied Social Psychology, 29, 2107-2142.

Takushi, R. Y., Neighbors, C., Larimer, M. E., Lostutter, T. W., Cronce, J. M., \& Marlatt, G. A. (in press). Indicated prevention of problem gambling among college students. Journal of Gambling Studies.

Van Empelen, P., Schaalma, H. P., Kok, G., \& Jansen, M. R. J. (2001). Predicting condom use with casual and steady sex partners among drug users. Health Education Research: Theory and Practice, 16, 293-305.

Volberg, R. A. (1996). Prevalence studies of problem gambling in the U.S. Journal of Gambling Studies, 12, 111-128.

Winters, K. W., Bengston, P., Dorr, D., \& Stinchfield, R. (1998). Prevalence and risk factors of problem gambling among college students. Psychology of Addictive Behaviors, 12, 127-135.

Received April 29, 2002

Revision received July 27, 2002

Accepted August 2, 2002 